\title{
Research on compression-rod lock-release mechanism with large load for space manipulator
}

\author{
Fei Yang ${ }^{1} \cdot$ Honghao Yue ${ }^{1} \cdot$ Yuliang Zhang $^{2} \cdot$ Jun $\mathrm{Wu}^{2} \cdot$ Zongquan Deng $^{1}$
}

Received: 4 April 2017 / Accepted: 12 November 2017/Published online: 29 January 2018

(C) The Author(s) 2018. This article is an open access publication

\begin{abstract}
With the development of Chinese space station, the space manipulator with large load plays a more and more important role. At the same time, the lock-release mechanism for the space manipulator must be reliable. In this study, the locking point layout method was proposed according to the size and the structure of the space manipulator, and the number and the position of the lock-release mechanism were determined. The design of lock-release mechanism including compression rod for large load lock-release was presented. By the established finite element models of lock-release mechanism and space manipulator, the locking stiffness and reliability was verified. A test prototype of the lock-release mechanism was developed. Through the stiffness measured in each direction, the accuracy of the stiffness and the strength were tested. At last, a space arm vibration test under lock status was carried out. The results show that the lock-release mechanism can meet the design specifications.
\end{abstract}

Keywords Space manipulator $\cdot$ Lock-release mechanism $\cdot$ Pyrotechnic device $\cdot$ Analysis and simulation

\section{Introduction}

With the rapid development of deep space exploration technology [1-4], especially the construction and application of space station, space shuttle and space robot, space manipulator [5-7] which has been used widely in space has become an indispensable part of on-orbit servicing systems such as the construction for space station. According to China's space master engineering plan, astronauts will work on the space station for a long time in the future, and the space manipulator will be one very important tool to help astronauts to act in extravehicular environment.

During the course of transporting and launching, the space manipulator will bear inertial force, vibration and impact load [8, 9]. For safety, space manipulator will be

Technical Editor: Fernando Antonio Forcellini.

Fei Yang

yf2003420@163.com

1 State Key Laboratory of Robot Technology and System, Harbin Institute of Technology, Harbin 150080, People's Republic of China

2 Beijing Satellite Manufacturing Factory, Beijing 100094, People's Republic of China folded and locked while launching by lock-release mechanism (LRM) [10-12]; when the space manipulator reaches at the pre-planned position in space, the LRM unlocks the folded manipulator to make it carry out the space missions. To ensure that the space manipulator can reach the space station smoothly, space manipulator must be locked reliably to resist the large impact load while launching. Generally speaking, more than one LRM are adopted at multiple locking points to lock the space manipulator for higher system stiffness, however, multiple LRMs will bring one enormous challenge for unlocking successfully at one time, thus one LRM will be single failure point, each LRM is related to the successful unlocking of the folded manipulator.

At current, the LRMs, which are widely used in aeronautic and aerospace field, are mostly based on the principle of initiating action [13-15] with the advantages of simple structure, large load, rapid separation and so on. Although the initiating devices are mature products, these devices have some disadvantages of severe impact, obvious pollution, non-repeatable usage and so on. At present, the research on LRM of large space manipulator in China is in blank state, the LRM with the property of large load, locking and unlocking reliably will promote space manipulator's engineering in the future application. 


\section{Design of the lock-release mechanism}

The space manipulator consists of high strength arm and concentrated mass. And the joints and the end effectors are high-density mass points, and each joint is connected in series into a manipulator with multiple degrees of freedom. The space manipulator is in the folding state while launching, the joints of the end effector on both sides are bended, and the whole mechanism lies on the cylindrical body surface. Considering the spatial configuration and mass distribution of the manipulator, the location of the locking mechanism according to the division is shown as Fig. 1.

According to the property of space manipulator and the rocket, the design requirements of the LRM are as follows:

1. The fundamental frequency of the manipulator in locked state is not $<70 \mathrm{~Hz}$;

2. The total mass of the lock-release mechanism is $<20.1 \mathrm{~kg}$;

3. The preload force error of the lock-release mechanism is $<5 \%$;

4. The structural rigidity of the lock-release mechanism is not $<5.0 \times 10^{6} \mathrm{~N} / \mathrm{mm}$.

\section{Design of LRM}

The LRM is a reliable rigid locking device that is connected by a compression rod and released by a pyrotechnic cutter. This device can achieve the locking between the side wall of the spacecraft and the payload by the screw connection of the compression rod [16-18]. When the manipulator reaches the designated working area, the electric detonator is ignited, and the cutter cuts off the

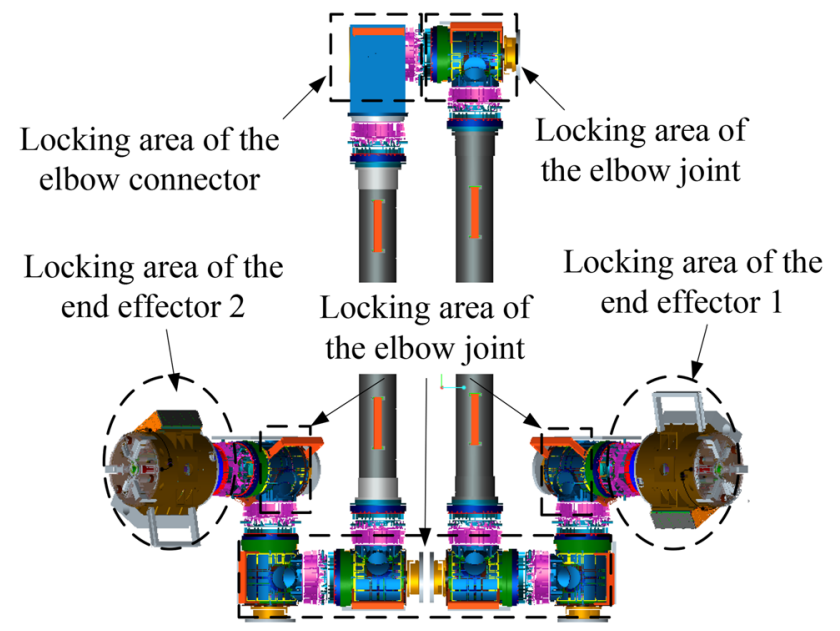

Fig. 1 Locking area distribution of manipulator compression rod at high speed causing by explosive gas, so that the original fixed restraint is released and the release of the payload is realized.

The principle of the LRM is to provide a pressing force through the compression rod assembly to maintain sufficient positive pressure on the two contact surfaces that need to be locked. The compression rod carries the axial load of the separation surface, and the friction of the contact surface or the positioning surface carries the lateral load. One end of the compression rod connects to the base and the other end provides compressing payload to achieve a rigid connection. The external structure design is shown in Fig. 2.

\section{Upper and lower bases}

The upper base is connected to the mechanical interface on the side of the arm by 6 M6 screws. The lower base is connected with the cabin bracket by $6 \mathrm{M} 8$ hexagon screws. An insulating pad is arranged on the connecting surface of the LRM to prevent the influence of the heat source on the robot arm. The upper and lower bases are positioned by a trapezoidal groove. The advantage is that it has a positioning effect on the lateral direction and can provide a specific shear resistance in the compacted state to ensure that the bending moment load would not affect the bearing rod in the locking mechanism. The placement of the upper and lower base can divide the impact load to the two opposing locking mechanism. The design reduces the load bearing requirements on the monomer-locking mechanism.

2. Compression rod and nuts

The pressing rod is the main bearing member of the LRM, whose diameter is $4 \mathrm{~mm}$ at the minimum cross section. The pressing rod is connected to the upper and lower bases by loading nuts and the preload force is applied. Glue is applied to the connection between the pressure rod and nuts to prevent connection failure.

3. Pyrotechnic cutter

The cutting cutter uses gunpowder explosion to promote the cutter to break the titanium alloy compression rod and the cutting reliability is greater than or equal to 0.9993 .

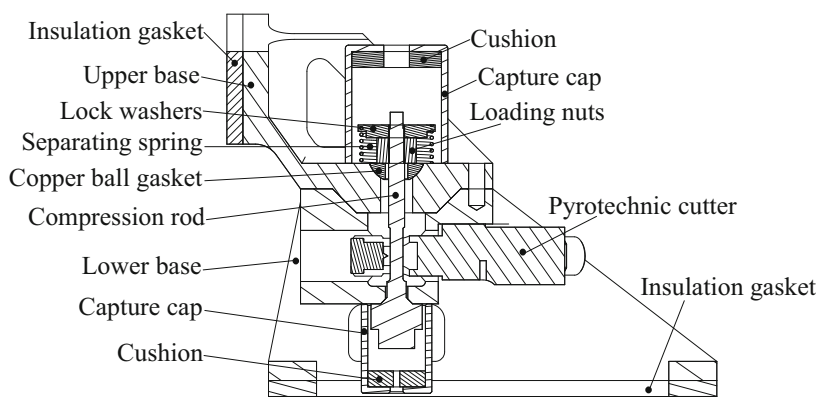

Fig. 2 Components of the LRM 
4. Lock washer and spring

The separation spring can send the broken piece of the compressing rod into the capture cap to prevent interference on the separation surface, which may stuck the robot arm. It is necessary to reserve enough space considering the shape changing of the compression rod broken bar after the cut off.

\section{Copper ball gasket}

The copper ball gasket, which can reduce the additional bending moment of the locking rod due to the deformation during the loading process, cooperates with the upper separation socket. The self-centering effect of the ball gasket will improve the stress state of the compression rod.

\section{Simulation analysis of dynamic characteristics}

\subsection{Static load analysis of the LRM}

The LRM is mounted below the joint of the manipulator, which is primarily responsible for the dynamic load generated by the acceleration of the joint. The load acts on the upper flange surface, and the confinement surface is the upper surface of the base. The material of LRM and space manipulator is $2 \mathrm{~A} 14 \mathrm{~T} 6$, and the material of compression rod in the locking mechanism is TC4, as shown in Table 1. The finite element model is shown in Fig. 3.

The load and constraint of the finite element model is set. The calculation results show that the load in the $X$ direction is $1393 \mathrm{~N}$ and the load in the $Z$ direction is $1500 \mathrm{~N}$, respectively, which are shown in Figs. 4 and 5.

From the results of the stress analysis, it can be seen that the maximum stress of the LRM occurs on the main bearing compression rod under the equivalent static load, and it does not reach the ultimate stress of the material, which means that the locking part can be locked. At the same time, the stiffness of the LRM in the $X$ and $Z$ directions can be calculated according to the stress-strain cloud diagram of the locking mechanism, as shown in Table 2. The values in the table uses the smaller one between the tension and compression state of $X$ or $Z$ direction.

\subsection{Analysis on dynamic response of the manipulator under locking condition}

The space manipulator is fixed by 14 LRMs on the base of the deck, and the finite element mesh of the manipulator under the locked condition using PATRAN is shown in Fig. 6.

The random vibration can check the stability of the connection between the components of locked manipulator. Therefore, a random vibration load is applied to the model, which is shown in Table 3 .

Analysis also is done by applying sinusoidal vibration load to the finite element model of the manipulator in $X$, $Y$ and $Z$ directions. The maximum resistance force values of the locking points of each locking mechanism are shown in Table 4.

\section{System test}

\subsection{Pre-tightening force control test of lock- release mechanism}

To ensure the correct preload of the lock-release mechanism, the loading capacity and the loading rigidity of a single locking mechanism needs to be confirmed. Therefore, the tightening force control requirement of the LRM should be within $\pm 5 \%$ [19]. In the early research, the torque wrench was used to apply constant torque; however, the loading error was difficult to control in this way. According to the structural characteristics of the lock-release mechanism, the displacement of the test point is used to determine the preload.

The loading device of LRM based on the above principle is consist of loading board, loading rack, laser displacement sensor and others, which is shown in Fig. 7. The LRM is fixed on the loading board. In the loading process, the laser displacement sensor detects the displacement of upper surface of compression rod all along.

To calibrate the magnitude relation between the displacement amount of the clamping rod/load lever end face and the actual preloaded force, the main bearing bar is pasted on the strain gauges to record the data of laser displacement sensor and the corresponding points of strain gauge in the loading process. The actual loading mechanism of LRM is shown in Fig. 8 below. The measuring
Table 1 Material property parameters for LRM and space manipulator

\begin{tabular}{lllll}
\hline No. & Material name & Elastic modulus $(\mathrm{GPa})$ & Poisson ratio & Yield strength (MPa) \\
\hline 1 & 2A14 T6 & 73 & $0.32-0.36$ & 415 \\
2 & TC4 & 110 & 0.34 & 860 \\
\hline
\end{tabular}


Fig. 3 Finite element model and loading setting mechanism of LRM

Fig. 4 Stress-strain cloud in

$X$ direction

Fig. 5 Stress-strain cloud in $Z$ direction
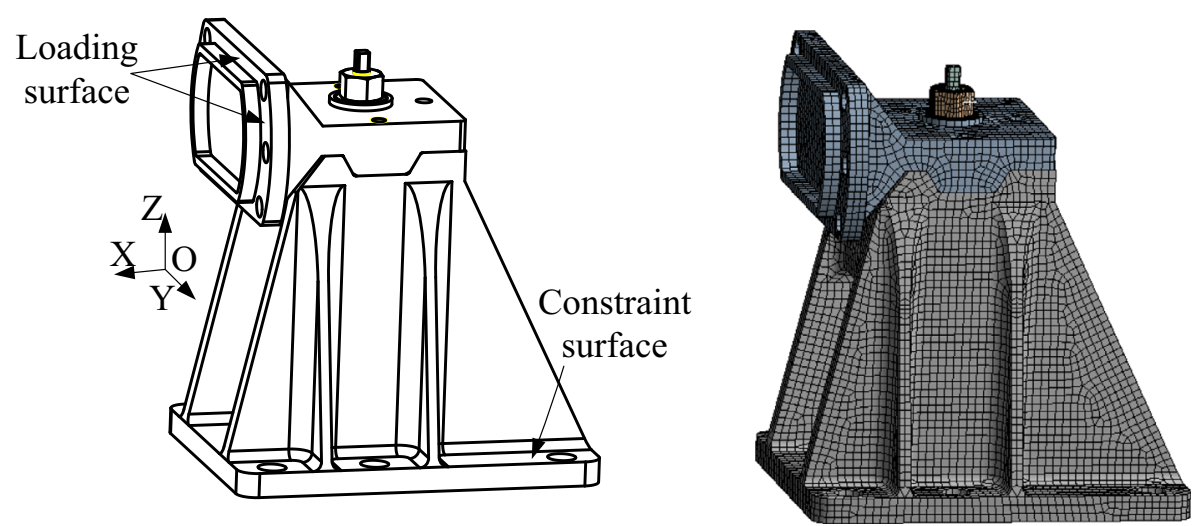
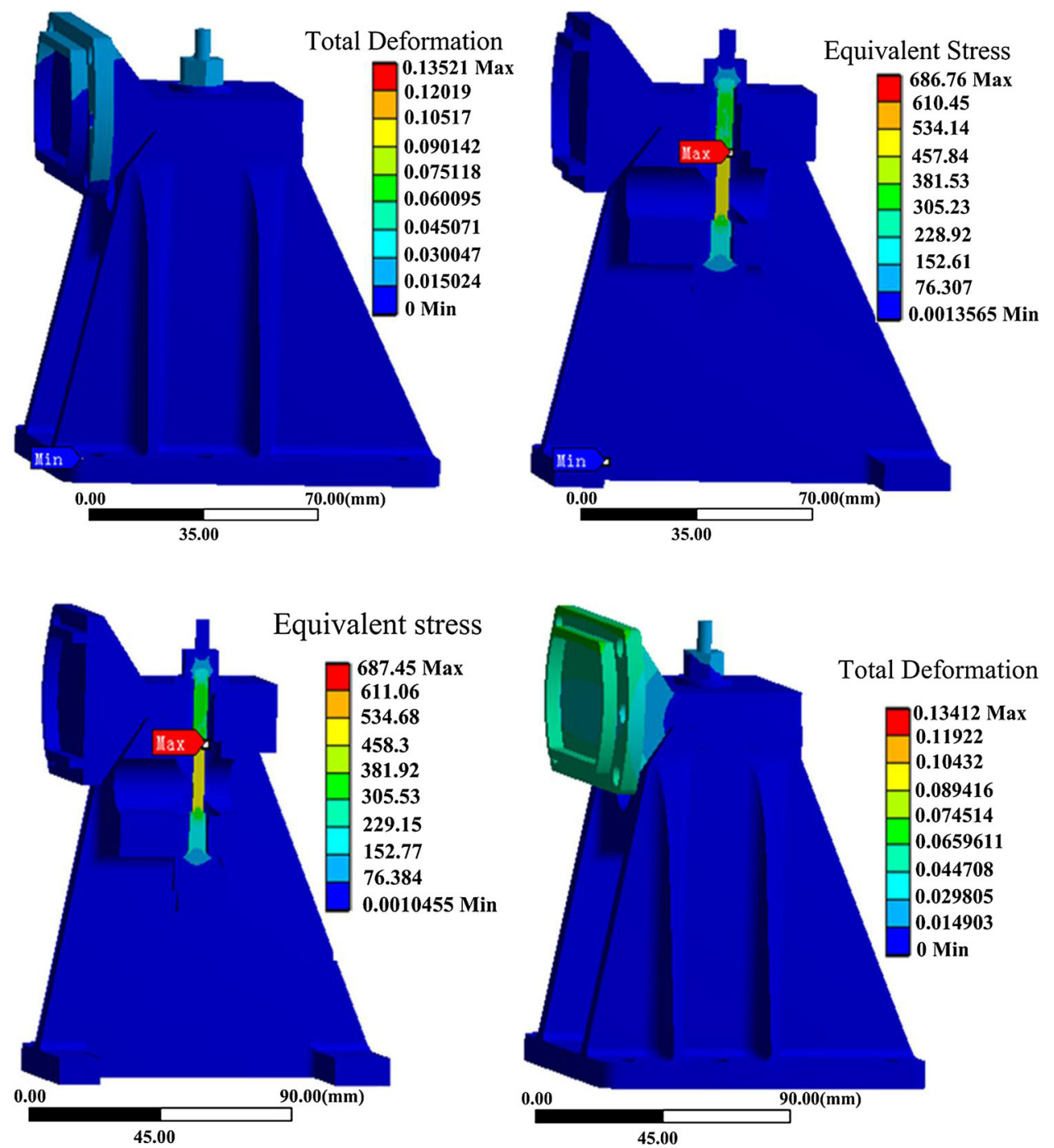

Table 2 Stiffness in $X$ and $Z$ directions of the LRM

\begin{tabular}{lll}
\hline & $X$ direction & $Z$ direction \\
\hline Loading force $(\mathrm{N})$ & 1393 & 1500 \\
Displacement $(\mathrm{mm})$ & $1.1 \times 10^{-1}$ & $1.2 \times 10^{-1}$ \\
Stiffness $(\mathrm{N} / \mathrm{m})$ & $1.3 \times 10^{7}$ & $1.25 \times 10^{7}$ \\
\hline
\end{tabular}

point of the LRM is the end of the load bar, and the measurement data points are recorded in Fig. 9.

The functional relationship between the preload stress and the displacement of the loading rod is given as

$\sigma=4774.4 \delta^{2}+1408 \delta+4.2019$. 


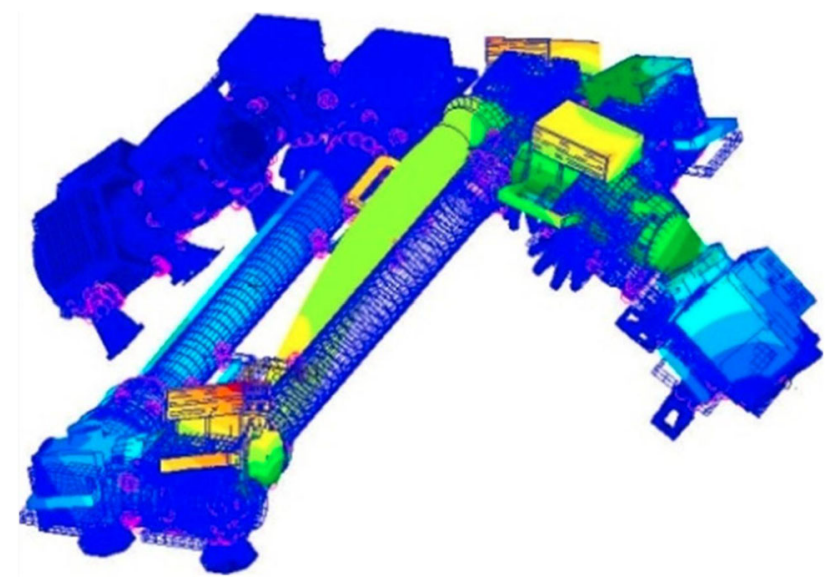

Fig. 6 Finite element model of manipulator in locked condition

Table 3 Random vibration condition of manipulator in locked condition

\begin{tabular}{lll}
\hline Direction & Frequency $(\mathrm{Hz})$ & Analysis conditions \\
\hline $\mathrm{X}$ & $20-50$ & $+3.808 \mathrm{~dB} / \mathrm{oct}$ \\
$\mathrm{Y}$ & $50-800$ & $0.032 \mathrm{~g}^{2} / \mathrm{Hz}$ \\
$\mathrm{Z}$ & $800-2000$ & $-3.808 \mathrm{~dB} / \mathrm{oct}$ \\
& Total arms' acceleration & $6.74 \mathrm{~g}$ \\
\hline
\end{tabular}

Table 4 The resistance force of LRMs under sinusoidal vibration load

\begin{tabular}{llll}
\hline Locking point & $X$ direction $(\mathrm{N})$ & $Y$ direction $(\mathrm{N})$ & $Z$ direction $(\mathrm{N})$ \\
\hline 1 & 1074.5 & 275.4 & 1065.8 \\
2 & 1008.3 & 325 & 1257.7 \\
3 & 755 & 1863 & 887 \\
4 & 2015 & 2522 & 2120 \\
5 & 3026 & 2310 & 2643 \\
6 & 2861 & 2400 & 2657 \\
7 & 2461 & 2483 & 2460 \\
8 & 2864 & 2610 & 2025.6 \\
9 & 2640 & 2160 & 2480 \\
10 & 3012 & 1934 & 2221 \\
11 & 2610 & 2448 & 2860 \\
12 & 736 & 2119 & 521 \\
13 & 1320.4 & 410 & 1500 \\
14 & 1393.1 & 340 & 1496 \\
\hline
\end{tabular}

According to the Eq. (1), when the preload stress reached $447 \mathrm{MPa}$, the displacement of compression rod end is $0.191 \mathrm{~mm}$. The displacement result is close to the finite element calculation, which is $0.185 \mathrm{~mm}$, indicating

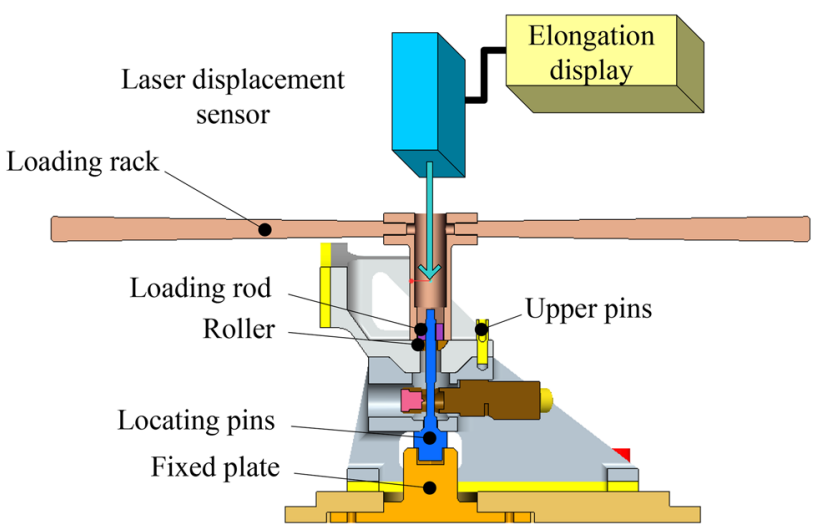

Fig. 7 Cross-section drawn of locking mechanism in loading

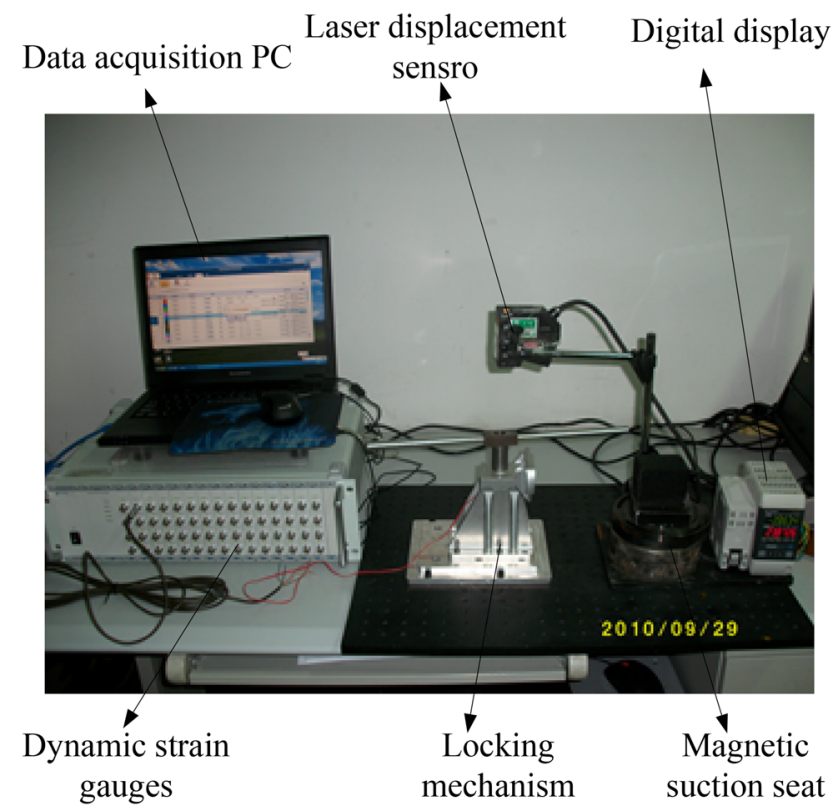

Fig. 8 Preloading mechanism of LRM

that the test did not appear theoretical bias. The error is mainly due to the workpiece size deviation and test device error. Repeating the loading test twice with the same loading process, the dynamic strain gauges show that the stress values are $458 \mathrm{MPa}$ and $462 \mathrm{MPa}$, respectively, and the calculation errors are 2.46 and $3.35 \%$, respectively; when the loading amount of the compression rod is $0.191 \mathrm{~mm}$, the error is less than the technical indicators required preloaded error of $5 \%$.

\subsection{Static load test of lock-release mechanism}

Static load test is that locking the fixed mechanism in the test device and applying loading on a specific surface by drawing press. The tensile/compressive load and load displacement are recorded during the test, and the 
Fig. 9 Recorded data points in loading process

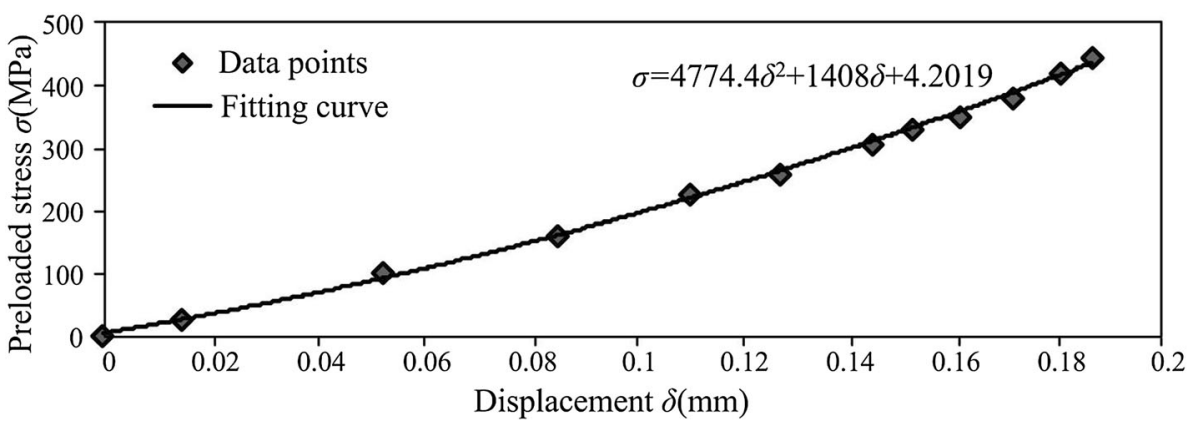

pull/pressure curves are obtained. The experiment is shown in Fig. 10.

The $X$ direction load is given on the flange of the upper base, and the $Z$ direction load is given on the top on the upper base (Fig. 11).

Through the test software, the relationship between the load in $X / Z$ direction and the displacement of the locking mechanism is obtained, and rigidity curve is drawn in Fig. 12.

By fitting the data, the relationship between the load in the $Y$ and $Z$ directions of the LRM are obtained as follows: $Y: f y=17,707 \delta-28.009$,

$Z: f z=72,046 \delta^{3}-19,365 \delta^{2}+4621.6 \delta-35.456$.

LRM

Test device

Fig. 10 Dead load test of locking mechanism

Fig. 11 Stiffness test of LRM. a Stiffness test in $X / Y$ b stiffness test in $Z$

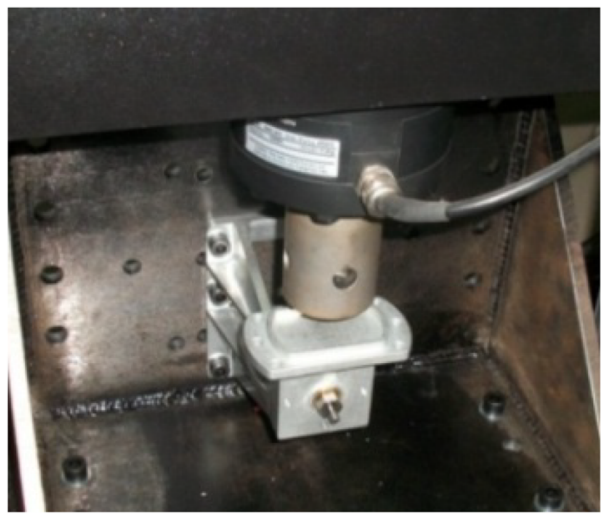

(a) Stiffness test in $\mathrm{X} / \mathrm{Y}$

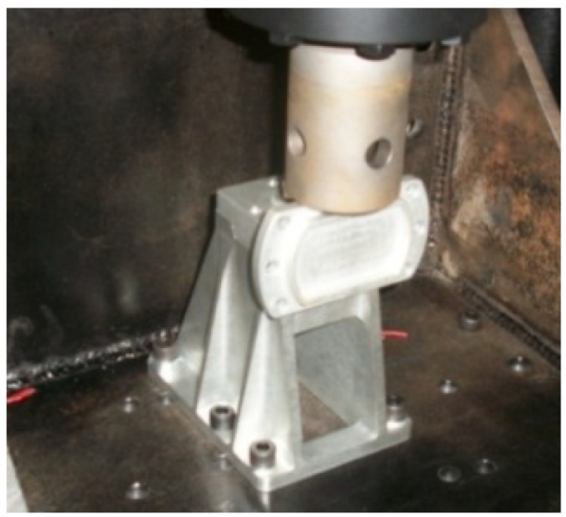

(b) Stiffness test in Z
Fig. 12 Stiffness test curve of LRM

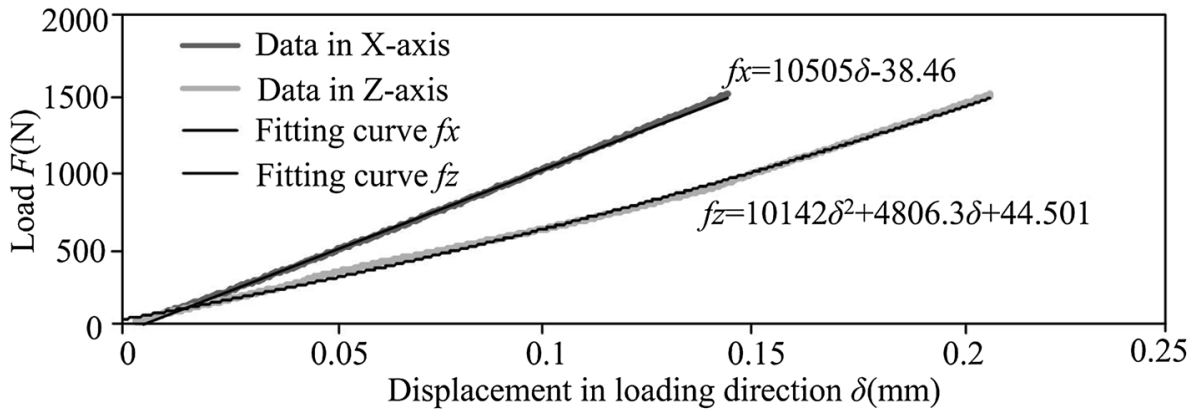


Fig. 13 Vibration test system

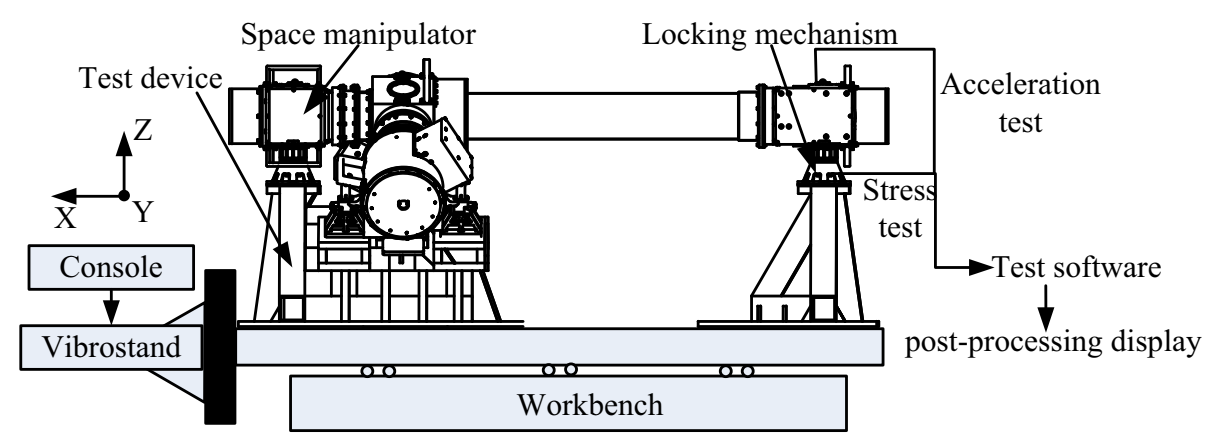

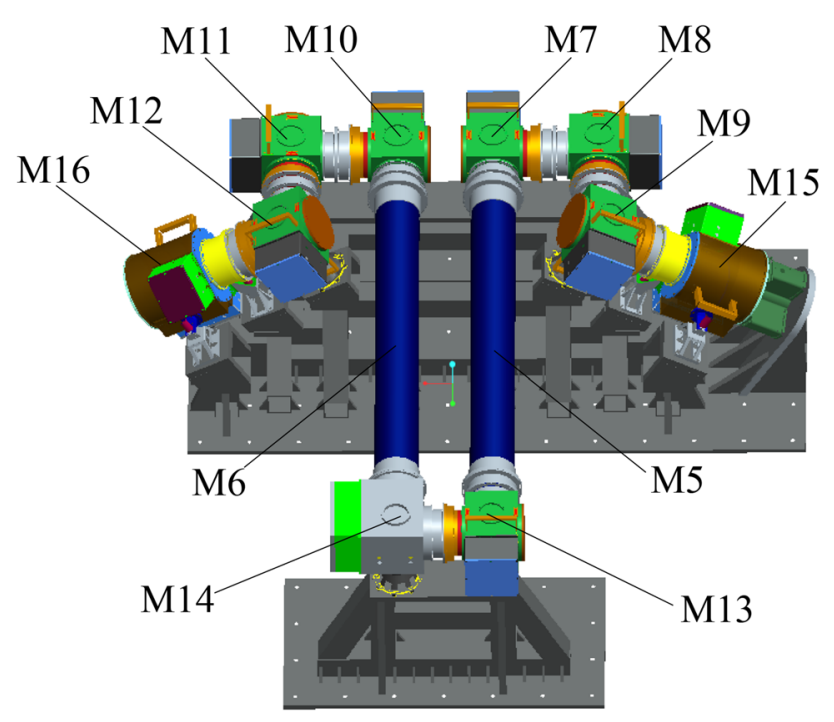

Fig. 14 Paste location of acceleration sensors

\subsection{Vibration test of the manipulator in the locked state}

The vibration test is carried out on a 40-ton vibration table of the mechanical environment test station in Changchun institute of optics and fine mechanics and physics, Chinese academy of science. The whole test system is shown in Fig. 13.

During the test, the test device is mounted on the vibration table by bolts. The control sensor is mounted on the vibration table and the direction is the same as the vibration direction. The rest of the acceleration sensor is placed on the shell surface of each joint of the manipulator. The sensors are attached as shown in Fig. 14 below, and the test is shown in Fig. 15.

Through the given input conditions, the sweep tests in the three directions are completed. The input of the $X, Y$, $Z$ three directions are shown in Table 5. The vibration test results of the $X, Y$ and $Z$ directions of the robot arm in the locked state are shown in Figs. 16, 17, and 18. The results of the vibration test of the acceleration sensor are listed. The frequency range is within $200 \mathrm{~Hz}$.

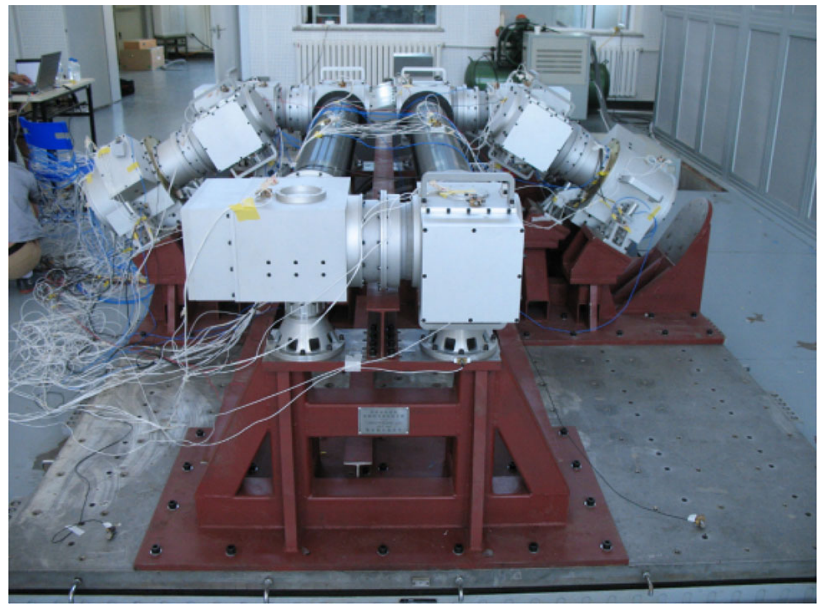

Fig. 15 The overall state of the test (14 LRMs)

Table 5 Input conditions for characteristic sweep test

\begin{tabular}{llll}
\hline Direction & Frequency $(\mathrm{Hz})$ & Amplitude $(\mathrm{g})$ & Scan rate $(\mathrm{Oct} / \mathrm{min})$ \\
\hline$X, Y, Z$ & $10-2000$ & 0.5 & 4 \\
\hline
\end{tabular}

From the curve results, it can be seen that the fundamental frequency in $X, Y$ and $Z$ directions are 84,105 and $87 \mathrm{~Hz}$, respectively, and the fundamental frequency in $X$, $Y$ directions are lower than the mechanical analysis of 89.2 Hz. The error is mainly due to the machining and assembly error of the prototype and the stiffness of the tooling during the test will affect the overall test results, resulting in a slightly lower resonant frequency. The data obtained from the experiment show that the fundamental frequency of the three directions of the manipulator is close to that of the finite element analysis, and the correctness of the analysis result is verified, the LRM meets the design requirement.

The sinusoidal vibration experiment is completed by the given inputs. The sinusoidal vibration stress test results of the two opposite LRMs are shown in Fig. 19.

The test data show that the stress of each LRMs does not exceed the ultimate stress of the material under given sinusoidal vibration loads. 
Fig. 16 Vibration test results in $X$ direction

Fig. 17 Vibration test results in $Y$ direction

Fig. 18 Vibration test results in $Z$ direction

Fig. 19 Stress test data of two LRMs of end joint
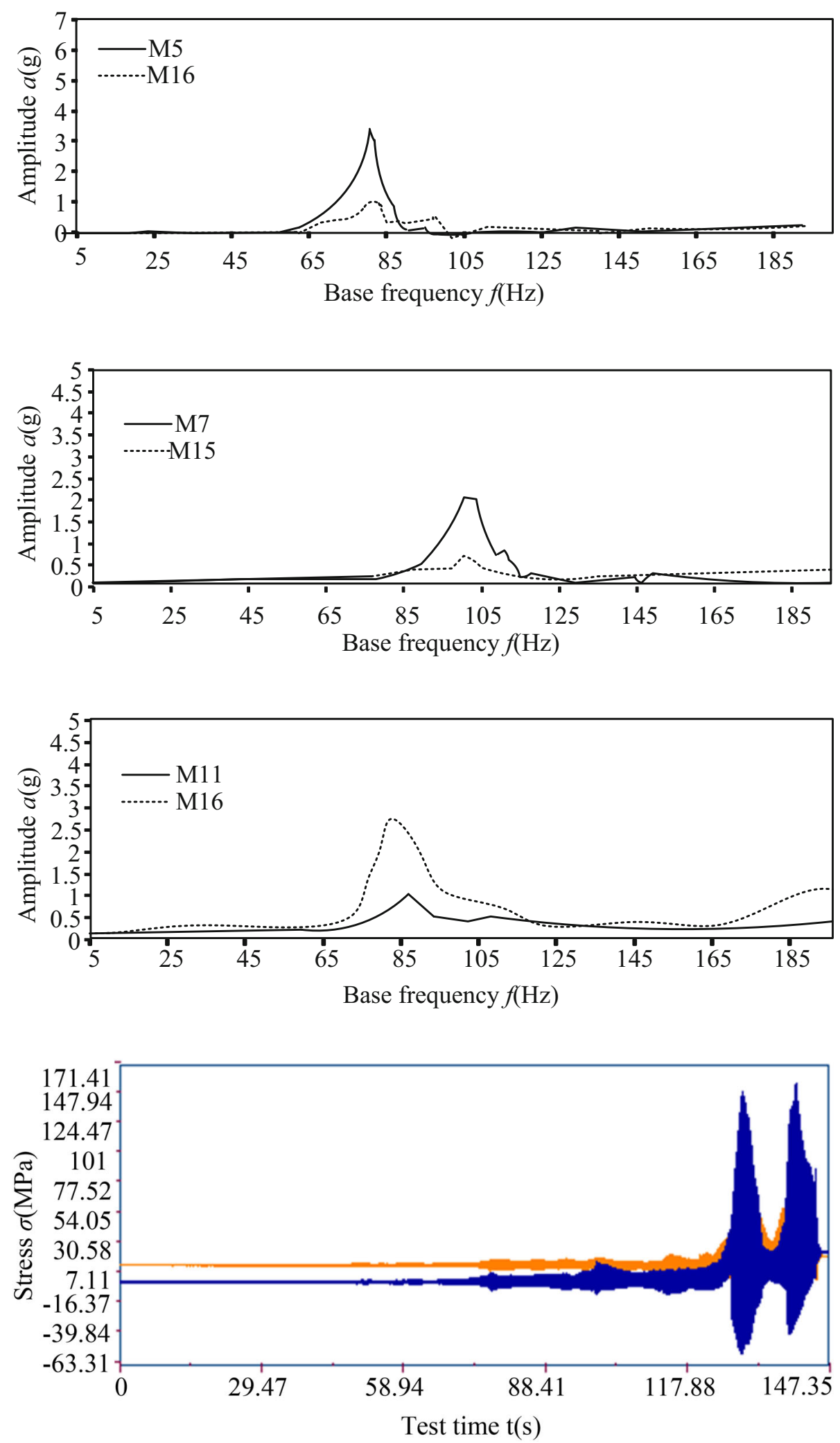


\section{Conclusion}

According to the reliable locking requirement for space manipulator during the launching course, one design of lock-release mechanism is presented. To ensure the locking stiffness for manipulator, upper base is connected to the lower base reliably by compression rod with enough preload. The finite element model of lock-release mechanism is established; the locking stiffness between upper base and lower base is verified. Multi-point distributed locking simulation model for space manipulator including 14 lockrelease mechanisms is built; the reaction force for 14 lockrelease mechanisms is obtained under sinusoidal vibration load. The principle prototype of lock-release mechanism is developed, and the locking stiffness is tested using tension machine. The space manipulator is locked by 14 lockrelease mechanisms and the test is carried out, the test results show that the lock-release mechanism can effectively ensure the structural safety of the space manipulator while launching.

Acknowledgements This work was financially supported by SelfPlanned Task (NO. SKLRS201614B) of State Key Laboratory of Robotics and System (HIT), the China Postdoctoral Science Foundation Funded Project (2015M580268), the Heilongiiang Postdoctoral Science Foundation Funded Project (LBH-Z15077) and the Fundamental Research Funds for the Central Universities (Grant No. HIT.NSRIF.201637).

Open Access This article is distributed under the terms of the Creative Commons Attribution 4.0 International License (http://crea tivecommons.org/licenses/by/4.0/), which permits unrestricted use, distribution, and reproduction in any medium, provided you give appropriate credit to the original author(s) and the source, provide a link to the Creative Commons license, and indicate if changes were made.

\section{References}

1. Viscio MA, Gargiolib E, Hoffman JA et al (2013) A methodology to support strategic decisions in future human space exploration: from scenario definition to building blocks assessment. Acta Astronaut 91:198-217

2. Tsuda Y, Mori O, Funase R et al (2013) Achievement of IKAROS-Japanese deep space solar sail demonstration mission. Acta Astronaut 82:183-188
3. Wilson JW, Clowdsley MS, Cucinotta FA et al (2004) Deep space environments for human exploration. Adv Space Res 34:1281-1287

4. Ehrenfreund P, McKay C, Rummel JD et al (2012) Toward a global space exploration program: a stepping stone approach. Adv Space Res 49:2-48

5. Zhao JL, Yan S, Wu JN (2014) Analysis of parameter sensitivity of space manipulator with harmonic drive based on the revised response surface method. Acta Astronaut 98:86-96

6. Toglia C, Sabatini M, Gasbarri P, Palmerini GB (2011) Optimal target grasping of a flexible space manipulator for a class of objectives. Acta Astronaut 68:1031-1041

7. Sabatini M, Gasbarri P, Monti R et al (2012) Vibration control of a flexible space manipulator during on orbit operations. Acta Astronaut 73:109-121

8. Zhang ZL, Dang YG, Zhou ML, Yu CG (2012) Simulation study of vibration characteristic for rocket launch container based on rigid and flexible coupled. J Syst Simul 24(11):2249-2254

9. Liao RD, Zhao Z, He K et al (2013) Random vibration analysis of cantilever structure on hydrogen cycle pre-cooling valves of rocket engine. Struct Environ Eng 40(2):1-6

10. Zhang XY, Yan XJ, Yang QL (2010) Design and experimental research of a shape memory alloy space release device with segmented nut form. J Mech Eng 46(17):145-150

11. Zhao Y (2011) Development of the space release device based on shape memory alloy. Harbin Institute of Technology, Harbin

12. Xuan M, Zhang DW, Gu S et al (2017) Design of hold-down and release mechanism for solar panel of micro-satellite. Opt Precis Eng 25(4):447-454

13. Wang JP, Yong YJ, Huang HJ (2013) Numerical simulation for impulsively loading mechanism of a point pyrotechnic separation device. J Vib Shock 32(2):9-13

14. Zhang G, Wang XY, Wang F et al (2017) Research on the response spectrum control method of pyroshock testing. Struct Environ Eng 44(3):38-45

15. Ye YK, Yan N (2010) Design and strength calculation of wedgetype pyrotechnic separation device. Initiat Pyrotech 5:1-4

16. Heemskerk CJM, Schoonejans PHM (1997) Overview of software engineering applications in the european robotic arm. In: Proceedings of the NASA 97 conference on data system in aerospace, Sevilla, Spain, pp 317-322

17. Dowen D, Christiansen S (2001) Development of a reusable, lowshock clamp band separation system for small spacecraft release applications. In: Proceedings of 9th European space mechanisms and tribology symposium, Liege, 19-21 Sept 2001. ESA SP-480

18. Deng ZQ, Wu BH, Wu X (2006) Design and analysis of anew style lock-unlock mechanism for space borne append ages. In: Proceedings of the international conference on advanced design and manufacture, pp 117-120

19. Robert RB, Huntsville A (1973) Docking structure for spacecraft. U.S. Patent No. $3,737,117$ 